\title{
Optimal Return Period to Encourage the Online Shopping Tendency of Potential Bangladeshi Consumers
}

\author{
Nafish Sarwar ${ }^{1}$, Mashruha Zabeen ${ }^{2}$, Husna Ara ${ }^{3}$ \\ ${ }^{1,2 \& 3}$ (Department of Business Administration, East West University, Bangladesh)
}

\begin{abstract}
Return policy is a promising catalyst to attract shoppers towards online purchasing since it compensates the dilemma of not examining the products physically before ordering. Objective of this research is to estimate an approximate return period expected by the potential Bangladeshi online shoppers to get rid of the inertia to go for adopting such recent shopping channel. Feasibility of that return period was also analyzed from retailers' point of view to determine an optimal value. An anonymous questionnaire was designed for data collection used in the survey conducted at random locations of Dhaka city during January and February, 2013 covering 120 participants aged above 20 years old, with Internet competency. The findings show that, a maximum of 30 days return period would be optimal for both consumers and retailers.
\end{abstract}

Keywords - Optimum Return Period, Online Shopping Tendency, Online Stores

\section{INTRODUCTION}

Due to modern developments on Internet technology, online shopping is growing at a rapid pace worldwide. Hence, investigating this phenomenon within Bangladeshi context is crucial considering that it is a relatively new trend in this country. However, absence of existing literature is a typical phenomenon for this kind of recent topics. Research conducted to date has been inadequate and moreover, very few studies on Bangladesh have been done. Therefore, to assist in filling up this gap, investigation on return policy from Bangladeshi viewpoint has been carried out. The research objectives are concerned with determining an optimal return period from both consumers' and retailers' perspective which would motivate shoppers to adopt and carry on using this modern shopping channel.

One of the major disadvantages of online shopping is not being able to touch and feel the product before ordering or purchasing. This is why online stores offer return policy which enables shoppers to return their product after purchasing within a given amount of time with guaranteed monetary refund. Although in most develop countries the process of receiving a cash refund from retailers in turn of previously purchased merchandise is a part of consumer right; many retailers in Bangladesh do not accept returns, though the customer has a receipt as a proof of purchase. According to their opinion a return is supposed to reduce the expected profit of the retailers' due to; opportunity costs (which includes re-purchasing cost) and depreciation costs (which includes re-packaging cost), given that the product has a similar supply-demand condition in market at the time of selling. This is why a return policy is one of the major issues in supply chain management.

However, for online shopping if the merchandise is in possibly being re-sellable condition and no more than a certain amount of time having passed since the purchase, then there is no better way but to offer a return policy, which in the long run helps the retailer to build a better customer-company relationship. And if the 'return' is compared as an interest free short term mortgaging of products to the consumers, then it actually gives an increment on the expected profit of the retailer.

\section{LITERATURE REVIEW}

There are three sections in the literature review segment. Section-1 is to identify the customers' point of view on return policy for online stores, while section-2 deals with retailers' perspective and section-3 sketches out the current scenario of Bangladeshi online stores.

\subsection{Consumers' Perspective:}

Apparently two main categories of risk emerge in the process of online shopping. The first is the risk associated with product and includes functional loss, financial loss, time loss, opportunity loss, and product risk; while the second is the risk associated with context of online transactions, and includes risk of privacy and security [1]. Among them, the influence of financial risk and product risk is significant [2 and 3]. Therefore, due to this inconvenience of consumers, it will be difficult for the online stores to reach their full potential since the bond of trust in the depersonalized setting of the Internet is quite fragile [4]. Hence, trust is one of the most important factors that influence customer purchasing decisions in Internet shopping. Apparently trust exerts a stronger effect on purchase intentions for both potential and repeat customers of an online store [5]. For that 
reason, the returns management process can significantly and positively influence repurchase behavior. By implementing a feasible policy of return, online stores can use it to their advantage in developing repeat and increased purchase behavior of their consumers [6]. Researchers suggested that, a tremendous advantage can be gained by the Internet firms if they could offer a return policy for build to order products; that offers the consumers the opportunity to customize the product according to the requirement; which would cause a significant increase in demand with some operational difficulties [7]. By creating a simple and hassle-free return policy and offering more shipping options can improve the satisfaction level of consumers with the experience of shopping online by more than $86 \%$ [8].

\subsection{Retailers' Perspective:}

Although companies are striving hard to ensure continuous quality improvement, necessity of product return policy still remains a reality. Companies view customers' product return as a major functional and financial trouble due to re-packaging, re-stocking and re-selling. To deal with this inconvenience, some companies take measures to discourage product-return which help to reduce the costs and frequencies of product-returns. For instance; limited time frames for returns (say, within 30days after purchase), product customization that allows return only when the product is defective, exchange for another identical or different item, and non-refundable purchase costs like shipping costs or re-stocking fees. However, from the marketing perspective, customer relationship is seen as a major prerequisite for business sustainability and profitability and a convenient product return policy can contribute to bring about positive company-customer relationship. Returning is generally offered by retailers as a courtesy to the customer. Despite the handling costs and revenues lost from returns, a return policy may have a positive impact on customers' adoption of online shopping channel by creating trust and minimizing risk factors. In the long run it may help the retailer to gain and retain customers and significantly increase long-term profits. By understanding the dimensions and outcome of product returns, retailers can determine the relationship between costs and benefits, which allows them to allocate resources more effectively to maximize profits. Online retailers can consider return as an interest free short term mortgaging of products to the consumers [9].

\subsection{Bangladesh Perspective:}

Like a lot of developed and developing countries, Bangladesh has viewed a remarkable growth in the technology-dependent communication medium, namely Internet [10]. In spite of several problems Bangladesh has seen phenomenal growth in online usage. Number of internet users per hundred inhabitants was 3 in 2010 while it was only 1 back in 2006 [11]. In consequence, the online shopping is considered as a useful and potential option along with the physical shopping channels. In fact, the online retail stores commenced a new door in the shopping of every day necessities of the general people. They offer worthy products at a fair price in a secured, convenient setting in order to survive and achieve profitability [12]. There are more than half a dozen pure online retailers, like HutBazar.com, Muktobazaar.com, Rokomari.com, Ajkerdeal.com, UpoharBd.com, GiftzHaat.com, BdStall.com etc, which are currently operating business in Bangladesh. An assortment of products for instance grocery and vegetables, fish and meat, bakery and sweets, gift items, cloths and accessories, electrical and electronics stuff etc are available to buy from these online stores.

But it is observed that many customers of Bangladesh who have Internet access are not aware of these online stores; more importantly even if they are aware, they are not interested to purchase from those stores [13]. As mentioned in literature review, trustworthiness and inability to physically examine the product remain as major reasons of customer inertia [13 and 14].

A few years back, the government of Bangladesh initiated a number of activities in creating a regulatory framework for trading over electronic media. In early 2010, a committee was set up to develop cyber law, but no substantial development has been made yet. Though there are no specific legal frameworks of international or national laws for online shopping, supplementary laws have been enacted in the progression in this country [14]. Furthermore, there is a non-government, voluntary organization Consumers Association of Bangladesh (CAB), which was established in 1978 to defend consumers' rights and interests in social, economic, health and environmental issues. But they too have taken very little attention regarding online shopping issue such as return policy, payment method, delivery timeframe etc.

Thus the responsibility lies largely on the shoulder of Bangladeshi online marketers to take effective steps towards maintaining and promoting the security, privacy and overall consumer rights in online shopping and to encourage the online shopping tendency of potential consumers.

Till date, very few research works focusing on a specific influencing factor on the online shopping tendency of Bangladeshi consumers have been carried out. Most of the researches have been conducted on issues such as practice of e-commerce, characteristics of e-commerce websites, online marketing, and online shopping intention among the Bangladeshi people and its supportive activities. Thus the available source of information on return period policy is the web sites of online retailers only. 
Table-2.1: Provision of Return Period by Noted Online Stores in Bangladesh

\begin{tabular}{|c|c|c|}
\hline Name of the stores & Return period & Website address \\
\hline BdStall.com & Not Available & http://www.bdstall.com \\
\hline GiftZHaat.com & 72 hours of delivery & http://www.giftzhaat.com \\
\hline HutBazar.com & Not Available & http://www.hutbazar.com \\
\hline iFeri.com & Not Available & http://www.iFeri.com \\
\hline Muktobazaar.com & $\begin{array}{l}\text { a. Perishable items such as meat, } \\
\text { fish, sweets, cakes, flowers etc } \\
\text { will not be changed or return } \\
\text { on received. } \\
\text { b. In case of gifts items or } \\
\text { clothing, inform within } 2 \\
\text { working days by mail or } \\
\text { phone. } \\
\text { c. In case of electric and } \\
\text { electronics products, warranty } \\
\text { provided by the dealers. }\end{array}$ & http://www.muktobazaar.com \\
\hline Rokomari.com & 30 Days Replacement Policy & http://rokomari.com \\
\hline UpoharBD.com & $\begin{array}{l}\text { a. Within } 12 \text { hours after delivery } \\
\text { to qualify for any refund } \\
\text { policy } \\
\text { b. Perishable items will be not } \\
\text { subject to any refund }\end{array}$ & http://www.upoharbd.com \\
\hline
\end{tabular}

Apparently, no study has been found that deals with the return policies and practices of online stores in Bangladesh. Hence, specific research is needed to probe the impact of product return policy and optimal return period to encourage the online shopping intention of potential consumers of Bangladesh.

\section{METHODOLOGY}

This cross-sectional study was conducted using self-administered questionnaires and convenient sampling method. A total of 150 questionnaires were distributed and 120 were collected back. The response rate was $80 \%$. Hence, the sample size for this research was determined at 120. An expected return period was determined from that survey. The target respondents in this research were Bangladeshi citizens, aged 20 years and older, who have access and are capable of using the Internet.

To study the feasibility of that return period from the retailer's perspective, it was assumed that the rational consumers are offered varieties of products by the retail store, and if the product is returned in sellable condition within a certain amount of time after purchasing with the proof of purchase, then the retailer offers a full cash refund. Since the re-purchase value or buyback price of the product is same as the selling price; then shortage of supply of the product will give an additional profit margin to the retailer, while shortage of demand of the product will cause the retailer loss. Therefore, it was also assumed that the supply-demand condition did not varied significantly within the time of returning.

\section{RESULTS AND DISCUSSIONS}

4.1 Estimation of desired return period (survey analysis-consumers' perspective):

Table-4.1 exhibits the demographic profile of the respondents who participated in the survey to assess consumers' perception on desired return period for online shopping.

Table-4.1: Respondents' Descriptive Statistics

\begin{tabular}{|lll|}
\hline Gender: & & \\
Male: & 93 & $77.5 \%$ \\
Female: & 27 & $22.5 \%$ \\
\hline Total & 120 & $100 \%$ \\
Occupation: & & \\
Service Holder: & 88 & $73.3 \%$ \\
Student: & 27 & $22.5 \%$ \\
Self Employed: & 03 & $02.5 \%$ \\
House Wife: & 02 & $01.7 \%$ \\
Total & 120 & $100 \%$ \\
Education: & & \\
Below Under-Grad: & 02 & $01.7 \%$ \\
Under Graduation: & 48 & $40.0 \%$ \\
Post Graduation: & 68 & $56.6 \%$ \\
PHD: & 02 & $01.7 \%$ \\
Total & 120 & $100 \%$ \\
\hline
\end{tabular}




\begin{tabular}{|lll|}
\hline Age: & & \\
$20-24:$ & 16 & $13.3 \%$ \\
$25-29:$ & 66 & $55.0 \%$ \\
$30-34:$ & 27 & $22.5 \%$ \\
$35-39:$ & 07 & $05.8 \%$ \\
$40-44:$ & 02 & $01.7 \%$ \\
$45-50:$ & 02 & $01.7 \%$ \\
\hline Total & 120 & $100 \%$ \\
\hline
\end{tabular}

To assess the customers' perception on the importance of product return policy, Non-Parametric Chisquare Test has been conducted. The test variables were product return in case of any defect and product return in case of customer dissatisfaction. For both the cases, 1 to 10 rating scale was used to collect their opinion. Besides, a dichotomous question was used to measure whether offering desired return period has any positive impact on customers' online shopping tendency.

Table-4.2: Product Return Guarantee in Case of Def
\begin{tabular}{|l|l|l|l|}
\hline & Observed N & Expected N & Residual \\
\hline 1 & 1 & 12.0 & -11.0 \\
2 & 1 & 12.0 & -11.0 \\
3 & 1 & 12.0 & -11.0 \\
4 & 3 & 12.0 & -9.0 \\
5 & 3 & 12.0 & -9.0 \\
6 & 3 & 12.0 & -9.0 \\
7 & 3 & 12.0 & -9.0 \\
8 & 10 & 12.0 & -2.0 \\
9 & 21 & 12.0 & 9.0 \\
10 & 74 & 12.0 & 62.0 \\
Total & 120 & & \\
\hline
\end{tabular}

Table-4.2 shows that, in case of product defect the respondents very strongly feel the necessity of return policy. Most of the frequencies were observed at points 9 and 10. On the other hand, a more flexible opinion towards product return is noticed in case the respondents do not like the product. And the frequencies of 7 to10 were higher as seen in Table-4.3.

Table-4.3: Product Return Guarantee in case of customers' dissatisfaction

\begin{tabular}{|l|l|l|l|}
\hline & Observed N & Expected N & Residual \\
\hline 1 & 3 & 12.0 & -9.0 \\
2 & 3 & 12.0 & -9.0 \\
3 & 3 & 12.0 & -9.0 \\
4 & 1 & 12.0 & -11.0 \\
5 & 12 & 12.0 & .0 \\
6 & 5 & 12.0 & -7.0 \\
7 & 16 & 12.0 & 4.0 \\
8 & 25 & 12.0 & 13.0 \\
9 & 16 & 12.0 & 4.0 \\
10 & 36 & 12.0 & 24.0 \\
Total & 120 & & \\
\hline
\end{tabular}

The result in Table-4.4 exhibits that potential customers responded positively towards online shopping when they are offered with desired return period. Two-third of the total respondents stated that they would consider online shopping as a convenient option.

Table-4.4: Online Shopping Tendency

\begin{tabular}{|l|l|l|l|}
\hline & Observed N & Expected N & Residual \\
\hline No & 7 & 40.0 & -33.0 \\
May & 38 & 40.0 & -2.0 \\
Be & 75 & 40.0 & 35.0 \\
Yes & 120 & & \\
Total & & \\
\hline
\end{tabular}


To estimate the customers desired return period for online shopping, the surveyed individuals were asked to mention the exact amount of days (open ended), which they would consider to be satisfactory. 20\% of the respondents believed that they would prefer the return period being 1-3 days, while some 9\% wished that the return period be 4-6 days. However, most of them (37\%) answered that exactly 7 days would serve their purpose, which means two-third of the total respondents are satisfied within one week time frame. Another $14 \%$ of them thought that the return period should be between 10-15 days. One-tenth of the sample mentioned they would like it to be 30 days. The remaining $10 \%$ were considered as non-respondents who were in doubt about the exact return period and according to them, it would depend on the category of the offering.

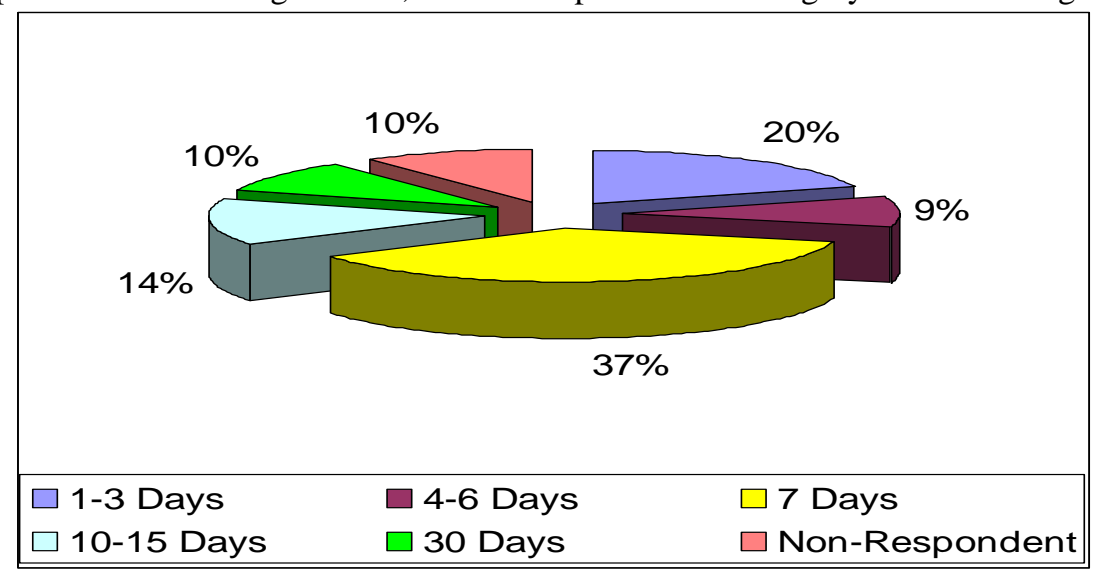

Figure-1: Respondents' Desired Return Period Based on Survey Data

The survey data reveals that the respondents' maximum desired return period is 30 days and none of them actually wanted more than that. More interestingly a return period of 15 days would satisfy $80 \%$ of the total respondents, whereas exactly two-third would be satisfied with a return period of 7 days. The current return period offered by most of the online stores in Bangladesh is 3 days, which can merely satisfy $20 \%$ of the respondents. Therefore, an optimal extension of the existing return period might be considered as an applicable decision to attract the buying tendency of the potential online consumers.

\subsection{Estimation of feasible return period (hypothetical analysis-retailers' perspective):}

A hypothetical analysis was done to estimate the return period that might be feasible for retailers to offer. It was assumed that a return is supposed to reduce the expected profit of the retailers' due to the depreciation costs only (which includes re-packaging cost also). It was also supposed that there were no significant changes in the supply-demand conditions of the market from the time of selling of the products, while the return was made. Therefore, the return now can be compared as an interest free short term mortgaging of products to the consumers to counter-balance this reduction in expected profit. It was also considered that only the purchase costs like shipping, delivery or, transportation are to be non-refundable yet the retailer would offer full money back within a limited time frames for returns, provided that the product is returned in resellable condition. However this analysis does not consider the increase in sell due to goodwill developed caused by this time frame and the opportunity costs of re-purchasing and re-selling.

The notations used in the model are as follows:

$\mathrm{i}=$ interest rate

$\mathrm{r}=$ depreciation rate of product

$\mathrm{N}=$ maximum time for return from the time of purchasing

So, now if the retailer does not allow any kind of change in the expected profit; then to stay at breakeven the following condition has to be accomplished.

$$
\begin{gathered}
{[1+\mathrm{i}]^{(365 / \mathrm{N})}+[1-\mathrm{r}]^{(365 / \mathrm{N})}=2} \\
\text { Where, } 0 \leq \mathrm{r} \leq 1
\end{gathered}
$$

Here $N \geq 0$, for any positive value of "i". Now the equilibrium analysis of this equation is done in the following sections with different values of " $r$ ".

Case-1: $(\mathbf{r}=\mathbf{0})$ When $\mathrm{r}=0$, then $[1+\mathrm{i}]^{(365 / \mathrm{N})}=1$; that is $(365 / \mathrm{N})=\ln (1) / \ln (1+\mathrm{i})=0$; therefore $\mathrm{N}=\infty$. That is if the product has a zero depreciation rate then, the maximum time for return from the time of purchasing that can be allowed by the retailer is unlimited. Since, for the products like gold or others which actually have appreciation value will give raise in expected profits of the retailer if the products are returned within the original price. 
Case-2: $(\mathbf{r}=\mathbf{i})$ When $\mathrm{r}=\mathrm{i}($ say $6 \%)$, then $[1+\mathrm{i}]^{(365 / \mathrm{N})}+[1-\mathrm{i}]^{(365 / \mathrm{N})}=2$; that is $(365 / \mathrm{N})=1$; therefore $\mathrm{N}$ is one year. It is quite natural as the depreciation of the product in a year would be exactly counter balanced by the mortgage effect in that year.

Case-3: $(\mathbf{r}=\mathbf{5 0 \%})$ When $r=0.5$, then for $6 \%$ interest rate $[1.06]^{(365 / \mathrm{N})}+[0.5]^{(365 / \mathrm{N})}=2$; to be precise $(365 / N)=11.9$; therefore $N=30.68$ days. After this stage with the further increments in value of " $r$ ", the value of " $\mathrm{N}$ " does not changes that significantly.

Case-4: $(\mathbf{r}=\mathbf{1 0 0} \%)$ When $r=1.0$, then $[1+i]^{(365 / N)}=2$; that is $N=[365 \times \ln (1+i)] /[\ln (2)]$. For $i=0.06$; the value of $\mathrm{N}$ is 30.6 days. That is for $6 \%$ interest rate, the maximum time for return from the time of purchasing has to be less than 30.6 days, but for $100 \%$ interest rate it can be as long as a year.

Case-4 was further analyzed for different values of "i" and Fig.2 exhibits that $N$ is directly proportionate with the values of "i".

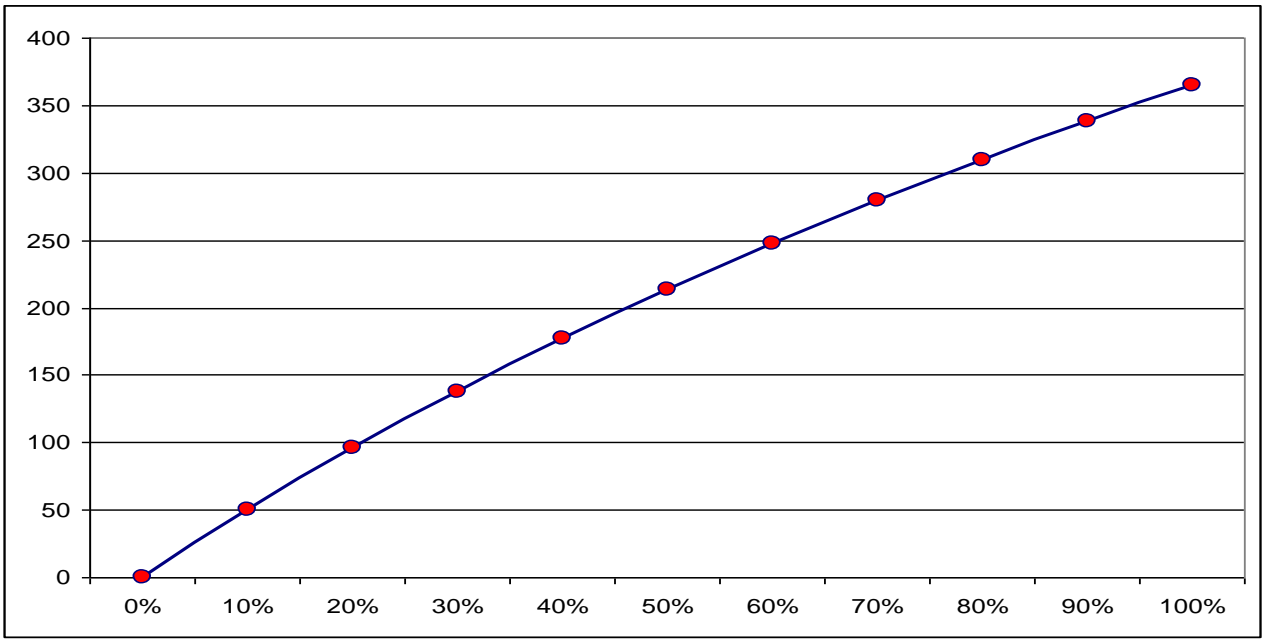

Figure-2: Effect of Interest Rate on Maximum Time for Return, at 100\% Depreciation Rate

[N (Days) -against- i (\%)]

The benchmark interest rate in Bangladesh is about $6 \%$. So the effect of depreciation rate on maximum time for return is analyzed thoroughly at $6 \%$ interest rate. Fig.3 exhibits that, when the depreciation rate is less than $30 \%$ then, with the increment of depreciation rate the maximum time allowance for return reduces rapidly. Moreover, when the depreciation rate is $30 \%$ then to remain in break-even for the expected profit the retailer might offer only 31 days of return period. After that the reduction rate of allowance in time frame gets moderately slow. For products with $100 \%$ depreciation rate the maximum allowance for return is only 30.6 days from the time of purchasing. Hence, it can be said that if the retailer (who is offering every kinds of products) does not want any significant reduction in the expected profit due to the return, can offer maximum time from the time of purchasing of 30 days only.

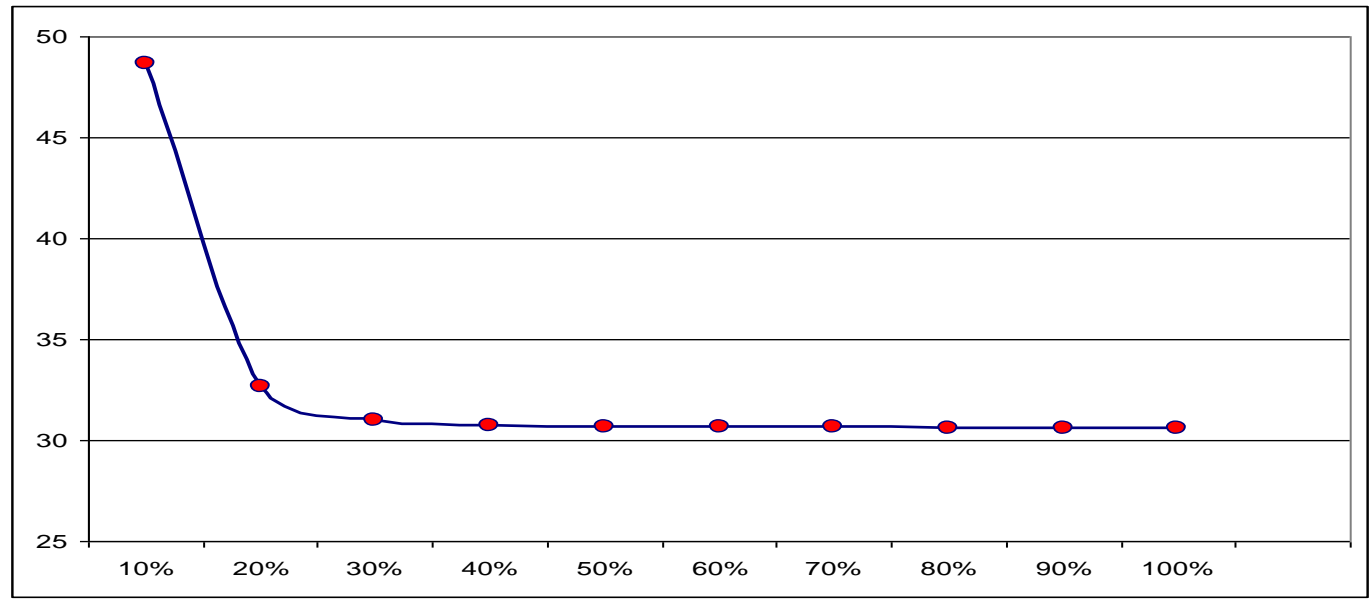

Figure-3: Effect of Depreciation Rate on Maximum Time for Return, for $6 \%$ Interest Rate [N (Days) -against- r (\%)] 


\subsection{Estimation of the Optimal Return Period:}

Considering the survey findings and the hypothetical analysis respectively from consumers' and retailers' point of view, it can be stated that a maximum of 30 days would serve the purpose. As the retailers deal with varieties of products, so a single depreciation rate is difficult to estimate. The maximum depreciation rate that a product may have is $100 \%$ and on that rate, retailers can offer 30 days return period without any financial loss (considering benchmark interest rate is 6\%). In cases where the depreciation rate is lesser than $100 \%$, the offered period can be extended. In view of customers' perception, none of them desired for more than 30 days return period. Hence, 30days can be considered as an optimal point where a win-win situation for both customers and retailers co-exist.

\section{CONCLUSION}

The findings will be valuable in providing new knowledge to retailers as well as consumers. Implementation of such return policy might help to grow significant numbers of online shoppers and sellers in Bangladesh. However, there are few limitations of this study. First of all this research was a cross-sectional study which was conducted only once from January to February 2013. Which means the findings might change with the evaluation criteria of the respondents. And secondly there might be a probability of achieving biased answers as the self-explanatory questionnaire provided some general information to ensure customers' understanding about online shopping.

Future research could expand the study to Bangladeshi people in other provinces except Dhaka, and compile all of them in together. Studies should also be repeated at regular intervals to monitor changes in online shopping behavior. Lastly, most studies on online shopping behavior have been quantitative. In order to gain a deeper understanding, there is a need for qualitative research studies that will provide richer details on perception, attitude and online shopping behavior in the Bangladeshi context.

\section{REFERENCES}

[1] Lee, D., Park, J., Ahn, J., 2001, The explanation of factors affecting e-commerce adoption. Proc. of the 22nd Intl. Conf. on Information Systems, pp. 109-120.

[2] Senecal, S., 2000, Stopping variables in online buying processes: An innovation diffusion approach. Proc. of the 6th Americas Conf. on Information Systems, pp. 1380-1385.

[3] Borchers, A., 2001, Trust in Internet shopping: A test of a measurement instrument. Proc. of the 7th Americas Conf. on Information Systems, pp. 799-803.

[4] Pravakar, P. R., 2000, Who owns the online consumer? Journal of consumer marketing 17 (2), 158-171.

[5] Kim, Hee-Woong, Xu, Y., Gupta, S., 2012, Which is more important in Internet shopping, perceived price or trust? Electronic Commerce Research and Applications 11 (3), 241-252.

[6] Griffis, S. E., Rao, S., Goldsby, T. J., Niranjan, T. T., 2012, The customer consequences of returns in online retailing: An empirical analysis. Journal of Operations Management 30 (4), 282-294.

[7] Mukhopadhyay, S. K., Setoputro, R., 2005, Optimal return policy and modular design for build-to-order products. Journal of Operations Management 23 (5), 496-506.

[8] Mielach, D., 2012, Want to sell more online? Accept More Return. Business News Daily 4 June. Available from <http://www.businessnewsdaily.com/2630-online-shopping-improvement.html〉. [15 February 2013].

[9] Petersen, J. A., Kumar, V., 2010, Can product returns make you money? MIT Sloan Management Review 51 (3), 85-89.

[10] Azam, Md. S., 2007, Internet Adoption and Usage in Bangladesh. Japanese Journal of Administrative Science 20 (1), $43-54$.

[11] Internet Users in Bangladesh: Number of internet users per 100 inhabitants, Worldstat info, 2010. Available from <http://en.worldstat.info/Asia/Bangladesh/Internet_users>. [February 28, 2013 ].

[12] Kashem, M. A., 2012, The Bangladeshi Consumer Behavior and Attitude toward Superstores. European Journal of Business and Management 4 (8), 85-94.

[13] Tsai, Y. C., Yeh, J. C., 2010, Perceived risk of information security and privacy in online shopping: A study of environmentally sustainable products. African Journal of Business Management 4 (18), 4057-4066.

[14] Rahman, H., Han, L., Customer satisfaction in E-Commerce: A case study of China and Bangladesh, doctoral diss. West Trollhättan, University, Sweden, 2011. 